\title{
Early Hyperglycemia in Diabetics as a Predictor of Disease Severity in COVID-19
}

\author{
Niaz Ahmed Shaikh, Arshee Khan, Asnin Shah, Rubina Inamdar, Rania Abusalma, \\ Rafeh Jamal
}

Dubai Health Authority, Rashid Hospital, Dubai, UAE

Email: thewonlees@gmail.com

How to cite this paper: Shaikh, N.A., Khan, A., Shah, A., Inamdar, R., Abusalma, R. and Jamal, R. (2021) Early Hyperglycemia in Diabetics as a Predictor of Disease Severity in COVID-19. International Journal of Clinical Medicine, 12, 543-550.

https://doi.org/10.4236/ijcm.2021.1212047

Received: November 11, 2021

Accepted: December 11, 2021

Published: December 14, 2021

Copyright $\odot 2021$ by author(s) and Scientific Research Publishing Inc. This work is licensed under the Creative Commons Attribution International License (CC BY 4.0).

http://creativecommons.org/licenses/by/4.0/

\begin{abstract}
Background: Hyperglycemia is an important predictor of prolonged hospitalization and mortality. The objective of this study was to analyze the role of early hyperglycemia in predicting the severity of COVID-19 illness and mortality. Method: Retrospective study on 259 patients with COVID-19 with measurement of average glucose during 24 hours of admission. Association of Early Hyperglycemia categorized as $<180 \mathrm{mg} / \mathrm{dl}$ or $>180 \mathrm{mg} / \mathrm{dl}$; was studied with mortality, requirement of ICU stay and prognostic markers. Results: Early hyperglycemia $(>180 \mathrm{mg} / \mathrm{dl})$ revealed a higher median value for CRP (109 mg/l [IQR; 48 - 199]) in comparison to $<180 \mathrm{mg} / \mathrm{dl}$ group ( $86 \mathrm{mg} / \mathrm{l}$ [IQR; $26.3-153]) \mathrm{p}=0.03$. ICU stay was higher in $>180 \mathrm{mg} / \mathrm{dl}$ group; 24 $(15.9 \%)$ vs 14 patients $(13 \%)$ [p $=0.51]$ in the $<180 \mathrm{mg} / \mathrm{dl}$ group. Mortality in the group $>180 \mathrm{mg} / \mathrm{dl}$ was $8(5.3 \%)$ while $<180 \mathrm{mg} / \mathrm{dl}$ had a mortality rate of $4(3.7 \%)$ [ $p=0.547]$. Conclusion: Hyperglycemia in the first 24 hours may anticipate an increased risk of ICU stay and a higher mortality rate. It may be a possible predictor of disease severity.
\end{abstract}

\section{Keywords}

Admission Hyperglycemia, COVID-19, Diabetes, Disease Severity

\section{Introduction}

The coronavirus disease of 2019 (COVID-19) has a diverse spectrum of clinical presentation, ranging from patients being completely asymptomatic carriers to exceedingly severe outcomes such as acute respiratory distress syndrome (ARDS) and multi-organ failure, necessitating ventilatory support and critical care [1]. While Chinese cohort studies demonstrated an intensive care unit (ICU) admission rate of $7 \%-26 \%$, the numbers ranged between $5 \%-12 \%$ of to- 
tal positive SARS-CoV-2 cases in Italy [2] [3]. Presence of comorbidities such as diabetes mellitus, hypertension, chronic obstructive pulmonary disease (COPD) and coronary artery disease (CAD) are independent risk factors for disease progression, in addition to age over 65 and male sex [4].

Admission hyperglycemia plays an important role in predicting mortality in hospitalized patients with COVID-19 [5]. It is also associated with increased incidence in mechanical ventilation and requirement of ICU stay [6]. Various meta-analyses done in different centers have recognized diabetes mellitus as significant comorbidity in COVID-19 [7] [8]. Paramount significance is the greater incidence of poor outcomes associated with diabetes mellitus, demonstrated by $44.5 \%$ of diabetics developing severe disease [7]. Similar findings have been reflected in a single-center, retrospective, observational study in China, where $22 \%$ of critically-ill COVID-19 patients who did not survive were diabetic [2]. Diabetes was reported in a greater proportion of critical and deceased patients in comparison to non-critical patients, reiterating the role of diabetes as a significant marker of poorer outcomes [9].

Early hyperglycemia as defined by high blood sugars $(>180 \mathrm{mg} / \mathrm{dl})$ on admission and during the initial 24 hours of admission, is postulated to affect the prognosis of these patients. This study aims at identifying the link between early hyperglycemia and the requirement of intensive care as well as with the mortality rate of the patients admitted with COVID-19. We postulate that early hyperglycemia may indirectly reflect the disease course and severity. If so, then timely intervention aimed at achieving optimal glucose control will promote better outcomes. Ascertaining the association between admission hyperglycemia and duration of hospital stay gives us the dual benefit of identifying uncontrolled blood sugars as a prognostic marker of COVID-19 severity and being able to initiate early and aggressive blood sugar control regimens, thereby reducing complications and improving patient outcomes.

\section{Objectives}

\section{Primary}

To explore the association between early hyperglycemia and adverse outcomes as measured by requirement of intensive care (ICU) and all causes of in-hospital mortality.

\section{Secondary}

To correlate the levels of prognostic markers such as C-reactive protein (CRP) and $\mathrm{D}$-dimer in these patients to reflect the inflammatory and prothrombotic state in patients with adverse outcomes.

\section{Methods}

\subsection{Materials and Methods}

This retrospective observational study included a total of 259 patients from one of the largest tertiary care centers in Dubai, United Arab Emirates caring for 
COVID-19 patients. Relevant data were collected from the electronic medical system.

Patients were included on the basis of World Health Organization (WHO) case definition of COVID-19 with laboratory confirmation of SARS-CoV-2 by real-time polymerase chain reaction (RT-PCR) of nasopharyngeal swabs or endotracheal aspirates, which were either known to be diabetic or presented with an $\mathrm{HbA} 1 \mathrm{C}$ above $6.5 \%$. Patients with no previous history of diabetes and $\mathrm{HbAlc}$ $<6.5 \%$ were excluded.

Blood glucose levels on admission and early blood glucose profile, defined as the mean of the blood glucose values in the first 24 hours of admission were collected. Hemoglobin A1C and prognostic markers such as C-reactive protein (CRP) and D-dimer were recorded. Duration of hospital stay and ICU stay was extracted. The primary endpoint was measured by all causes of in-hospital mortality and requirement of ICU stay.

Early blood glucose profile was categorized into two groups defined as average glucose $<180 \mathrm{mg} / \mathrm{dl}$ or $>180 \mathrm{mg} / \mathrm{dl}$. The subgroup was analyzed based on these two categories with two studied outcomes as defined by presence of mortality and requirement of ICU stay respectively.

\subsection{Statistical Analysis}

Continuous variables were presented as mean \pm SD or median $(\mathrm{Q} 1, \mathrm{Q} 3)$ as appropriate, and categorical data was organized into frequency and percentages. Independent sample $\mathrm{t}$-test and Mann Whitney test were used for studying numerical data for the categories of average blood glucose $<180 \mathrm{mg} / \mathrm{dl}$ or $<180$ $\mathrm{mg} / \mathrm{dl}$ as appropriate. Chi-squared analysis was used for studying the categories of glucose level with the categories of ICU stay and mortality. All tests were two-tailed and the p-value was considered significant at $<0.05$. Data entry and statistical analysis were carried out with SPSSv20.0 (IBM Corp, Armonk, NY, US). This study was approved by the Research and Ethical approval committee of Dubai Health Authority with reference number DSREC-06/2020_67.

\section{Results}

\subsection{General Characteristics of Patients}

In the 259 cases studied, 224 (86.5\%) were male. The mean age for our study sample was $50.5 \pm 12.3$ years. Median glucose on admission was $204 \mathrm{mg} / \mathrm{dl}$ [IQR; $145-285 \mathrm{mg} / \mathrm{dl}]$ and the mean HbAlc was $8.8 \% \pm 2.5 \%$. Median glucose in the first 24 hours was $205 \mathrm{mg} / \mathrm{dl}(139$ - 259). The median duration of hospitalization for the study sample was 13 days [IQR; 7 - 19 days]. 38(14.7\%) required ICU care during admission. Median duration of stay in ICU for such patients was 20.5 days [IQR; 13.7 - 28 days]. Laboratory parameters revealed a median C reactive protein of 98 [IQR; 35 - 183] and a median d dimer value of 1.1 [IQR; $0.54-2.5]$. Mortality was noted in 12 (4.65) of the patients. Baseline characteristics of all study subjects are presented in Table 1. 


\subsection{Hyperglycemia and COVID-19}

No consistent association between early hyperglycemia and the overall duration of hospitalization could be demonstrated. However, patients with early glycemic levels above $180 \mathrm{mg} / \mathrm{dl}$ demonstrated both a greater incidence of requiring intensive care and a longer duration of ICU stay.

24 patients $(15.9 \%)]$ of the group with glucose $>180 \mathrm{mg} / \mathrm{dl}$ required ICU care vs 14 patients $(13 \%)$ ] [ $\mathrm{p}=0.51$ ] in the group with glycemic levels $<180 \mathrm{mg} / \mathrm{dl}$. Patients with an early average blood glucose levels $>180 \mathrm{mg} / \mathrm{dl}$ were noted to have longer duration of ICU stay; 21 days [16.3 - 28.8 days] in comparison to 17 days [10.8 - 27.3] in the other group, $(\mathrm{p}=0.44)$ (Table 2).

Table 1. General characteristics of the study sample $(n=259)$.

\begin{tabular}{cc} 
Male Gender & $224(86.5)$ \\
Age (years ) & $50 \pm 12.3$ \\
Duration of stay in hospital in days & $13(7-19)$ \\
Patients requiring ICU stay & $38(14.7)$ \\
Duration of ICU stay & $20.5(13.7-28)$ \\
Admission glucose & $204(145-285)$ \\
Average Glucose over initial 24 hours & $205(139-259)$ \\
Hbalc & $8.8 \pm 2.5$ \\
C-reactive protein & $98(35-183)$ \\
D-dimer & $1.1(0.55-2.5)$ \\
Deceased & $12(4.6)$ \\
\hline
\end{tabular}

$\mathrm{n}$ is the number of cases, percentages expressed in parenthesis; normal distribution expressed as mean with standard deviation; skewed data as median with interquartile range.

Table 2. Comparison of study parameters based on average glucose in the initial 24 hours.

\begin{tabular}{cccc}
\hline & $\begin{array}{c}\text { Glucose }<180 \mathrm{mg} / \mathrm{dl} \\
\mathbf{n}=108\end{array}$ & $\begin{array}{c}\text { Glucose }>180 \mathrm{mg} / \mathrm{dl} \\
\mathbf{n}=151\end{array}$ & p value \\
\hline Male Gender & $94(87)$ & $130(86.1)$ & 0.83 \\
Age (years ) & $50.7 \pm 12.6$ & $50.4 \pm 12.1$ & 0.85 \\
Duration of stay in hospital in days & $12.5(7-18.7)$ & $13(7-20)$ & 0.7 \\
Duration of ICU stay & $17(10.8-27.3)$ & $21(16.3-28.8)$ & 0.44 \\
Admission glucose & $156.5 \pm 50.5$ & $292 \pm 150.1$ & $<0.001$ \\
Average Glucose over initial 24 hours & $134.8 \pm 23.7$ & $267.3 \pm 73.5$ & $<0.001$ \\
Hbalc & $7.3 \pm 1.6$ & $9.9 \pm 2.6$ & $<0.001$ \\
C-reactive protein & $86(26.3-153)$ & $109(48-199)$ & 0.03 \\
D-dimer & $0.97(0.5-2)$ & $1.2(0.6-2.8)$ & 0.15 \\
\hline
\end{tabular}

$\mathrm{n}$ is the number of patients, normal data as mean \pm standard deviation; skewed data as median (interquartile range). 
Prognostic markers were noted to be higher in the early hyperglycemia group with a median C reactive protein: 109 [IQR; 48 - 199] in comparison to 86 [IQR; $26.3-153]$ in the group with early blood glucose profile $<180 \mathrm{mg} / \mathrm{dl}(\mathrm{p}=0.03)$. Median D dimer was 1.20[IQR; 0.6 - 2.8] in comparison to 0.97 [IQR; 0.5 - 2.0] in the group with $<180 \mathrm{mg} / \mathrm{dl}(\mathrm{p}=0.154)$.

Chi square analysis revealed higher rate of mortality in the group $>180 \mathrm{mg} / \mathrm{dl}$; $8(5.3 \%)$ while the group with glycemic levels $<180 \mathrm{mg} / \mathrm{dl}$ had a mortality of 4 (3.7\%) [p $=0.547]($ Table 3$)$

\section{Discussion}

Our study observed the glucose readings in the initial 24 hours; this group was least likely to be affected by management with steroids. It was judged to be a more reliable reflection of the initial hyperglycemia in comparison to isolated admission glycemic reading. Early hyperglycemia could be explained by pre-existing uncontrolled diabetes or non-compliance to medications and in the light of pandemic; due to lack of access to medications. Nevertheless, role of stress hyperglycemia or new-onset diabetes cannot be understated [5]. In our population, the group without early hyperglycemia was noted to have a lower mean $\mathrm{HbAlc}$ which may indicate that prior glycemic control plays a role in the progression of the disease.

The group with early hyperglycemia had worse prognostic markers and in-hospital mortality. This indicates that higher glycemic levels during the initial hours may predict a poorer course of the disease. Admission hyperglycemia has been studied as a predictor of survival and risk of in-hospital complications and has been associated with increased mortality risks in acute coronary syndrome and in sepsis [10] [11]. Admission hyperglycemia has been studied as a predictor of radiographic imaging in COVID-19 patients, with acute hyperglycemia leading to the development and progression of ARDS in these patients [12]. A recent, retrospective analysis in Wuhan, China involving 605 COVID-19 patients without a prior diagnosis of diabetes demonstrated that the 28-day mortality was three-fold higher in patients with raised fasting glucose on admission (greater than or equal to $7 \mathrm{mmol} / \mathrm{l}$ ), thus establishing admission hyperglycemia as an independent predictor of 28-day mortality [13]. Our study was able to reflect concordant findings but couldn't achieve statistical significance.

Table 3. Chi-squared analysis of glucose levels with ICU stay and mortality.

\begin{tabular}{ccccc}
\hline & & Glucose $<\mathbf{1 8 0} \mathbf{~ m g / d l}$ & Glucose $>\mathbf{1 8 0} \mathbf{~ m g / d l}$ & p value \\
\hline Deceased & Yes & $4(3.7)$ & $8(5.3)$ & 0.547 \\
& No & $104(96.3)$ & $143(94.7)$ & \\
Required ICU stay & Yes & $14(13)$ & $24(15.9)$ & 0.511 \\
& No & $94(87)$ & $124(84.1$ & \\
\hline
\end{tabular}

Number in parenthesis indicates percentage. 
In our study, the presence of complicated disease course was studied by looking into the incidence of intensive care unit stay and mortality rates in patients with early hyperglycemia. 8 out of 151 (5.3\%) patients with early hyperglycemia died during hospital stay while the mortality rate stood at $3.7 \%$ in patients without early hyperglycemia, which is suggestive of raised mortality risk in patients who present with uncontrolled blood sugars. Poorer outcomes were also demonstrated in this group of patients with $15.9 \%$ requiring intensive care unit stay vs $13 \%$ of patients with average blood glucose $<180 \mathrm{mg} / \mathrm{dl}$ requiring critical care.

The role of specific biomarkers as predictors of disease severity is crucial in early identification and risk stratification in COVID-19 patients, and helps to facilitate early and appropriate intervention measures. Elevated C-reactive protein (CRP), procalcitonin, D-dimer and ferritin were linked to composite poor outcomes reflected by mortality, severe disease, ARDS and need for ICU care in COVID-19 patients [14]. In our study, we aimed to analyze the contribution of uncontrolled blood sugars in worsening the inflammatory and thrombotic state in COVID-19 by comparing the levels of CRP and D-Dimer in patients with and without early hyperglycemia. While hyperglycemia is still not widely accepted as a biomarker of severity, acute increase in blood sugars have been associated with a concomitant increase in inflammatory mediators such as IL-6 and D-dimer [15], which have been documented in COVID-19 patients with hyperglycemia. This is supported by the findings of our study, with a higher level of D-dimer being noted in patients with high early blood glucose profiles. In addition, patients with early hyperglycemia had a higher level of CRP that achieved statistical significance. Admission hyperglycemia may hence be a simple but significant predictor of the underlying inflammatory state in diabetic COVID-19 patients and should prompt aggressive blood sugar control strategies

\section{Limitations}

This was a retrospective study with information extracted from records. It was a single-center study. A multi-center study would be able to derive more conclusive data to support these findings. Other markers of inflammation were not studied which may have provided further light on this relationship. We have judged ICU stay as an indicator of severity which holds true for the majority of COVID-19 cases but also envelops the minority which may have required ICU care for reasons other than COVID-19. Confounding factors like chronic lung disease and hypertension; which may play a role in prognosis, were not adjusted in the results. This may have an impact on the findings but does not eliminate a relationship between hyperglycemia and COVID-19 severity.

\section{Conclusion}

Admission and early hyperglycemia may be used as a prognostic factor, affecting the course and outcome of the diabetic patients admitted with COVID-19 infec- 
tion. It is an early warning sign correlating with the outcome in diabetic patients with COVID-19 and may determine the outcome as uncontrolled blood sugars could worsen the inflammatory and pro-thrombotic state and results in greater morbidity and mortality. The role of blood sugars on admission needs to be studied further as a cheap and simple biomarker in Diabetic COVID-19 patients and should be used to raise vigilance and early intervention. Prolonged hospitalization and intensive care stay are reflectors of complex disease courses and increase the risk of further complications including hospital-acquired infections. The role of admission hyperglycemia, as a marker of severity in COVID-19, is a matter of great interest and potential, as it can provide an early clue in regard to patient prognosis.

\section{Conflicts of Interest}

The authors declare no conflicts of interest regarding the publication of this paper.

\section{References}

[1] Singhal, T. (2020) A Review of Coronavirus Disease-2019 (COVID-19). Indian Journal of Pediatrics, 87, 281-286. https://doi.org/10.1007/s12098-020-03263-6

[2] Yang, X., Yu, Y., Xu, J., Shu, H., Xia, J., Liu, H., et al. (2020) Clinical Course and Outcomes of Critically Ill Patients with SARS-CoV-2 Pneumonia in Wuhan, China: A Single-Centered, Retrospective, Observational Study. The Lancet Respiratory Medicine, 8, 475-481. https://doi.org/10.1016/S2213-2600(20)30079-5

[3] Guan, W., Ni, Z., Hu, Y., Hu, Y., Liang, Z., Liang, W., et al. (2020) Clinical Characteristics of Coronavirus Disease 2019 in China. The New England Journal of Medicine, 382, 1708-1720. https://doi.org/10.1056/NEJMoa2002032

[4] Cen, Y., Chen, X., Shen, Y., Zhang, X., Lei, Y., Xu, C., et al. (2020) Risk Factors for Disease Progression in Patients with Mild to Moderate Coronavirus Disease 2019-A Multi-Center Observational Study. Clinical Microbiology and Infection, 26, 1242-1247. https://doi.org/10.1016/j.cmi.2020.05.041

[5] Coppelli, A., Giannarelli, R., Aragona, M., Penno, G., Falcone, M., Tiseo, G., et al. (2020) Hyperglycemia at Hospital Admission Is Associated with Severity of the Prognosis in Patients Hospitalized for COVID-19: The Pisa COVID-19 Study. Diabetes Care, 43, 2345-2348. https://doi.org/10.2337/dc20-1380

[6] Sardu, C.D., Onofrio, N., Balestrieri, M.L., Barbieri, M., Rizzo, M.R., Messina, V., et al. (2020) Outcomes in Patients with Hyperglycemia Affected by COVID-19: Can We Do More on Glycemic Control? Diabetes Care, 43, 1408-1415. https://doi.org/10.2337/dc20-0723

[7] Hu, Y., Sun, J., Dai, Z., Deng, H, Li, X., Huang, Q., et al. (2020) Prevalence and Severity of Corona Virus Disease 2019 (COVID-19): A Systematic Review and Meta-Analysis. Journal of Clinical Virology, 127, Article ID: 104371. https://doi.org/10.1016/j.jcv.2020.104371

[8] Yang, J., Zheng, Y., Gou, X., Pu, K., Chen, Z., Guo, Q., et al. (2020) Prevalence of Comorbidities and Its Effects in Patients Infected with SARS-CoV-2: A Systematic Review and Meta-Analysis. International Journal of Infectious Diseases, 94, 91-95. https://doi.org/10.1016/j.ijid.2020.03.017

[9] Zheng, Z., Peng, F., Xu, B., Zhao, J., Liu, H., Peng, J., et al. (2020) Risk Factors of 
Critical \& Mortal COVID-19 Cases: A Systematic Literature Review and Meta-Analysis. The Journal of Infection, 81, e16-e25.

https://doi.org/10.1016/j.jinf.2020.04.021

[10] Deedwania, P., Kosiborod, M., Barrett, E., Ceriello, A., Isley, W., Mazzone, T., et al. (2008) Hyperglycemia and Acute Coronary Syndrome. Circulation, 117, 1610-1619. https://doi.org/10.1161/CIRCULATIONAHA.107.188629

[11] Nugent, K., Edriss, H. and Selvan, K. (2016) Hyperglycemia and Outcomes in Patients with Sepsis. Journal of Thoracic Disease, 8, E575-E577.

https://doi.org/10.21037/jtd.2016.05.63

[12] Iacobellis, G., Penaherrera, C.A., Bermudez, L.E. and Bernal Mizrachi, E. (2020) Admission Hyperglycemia and Radiological Findings of SARS-CoV2 in Patients with and without Diabetes. Diabetes Research and Clinical Practice, 164, Article ID: 108185. https://doi.org/10.1016/j.diabres.2020.108185

[13] Wang, S., Ma, P., Zhang, S., Song, S., Wang, Z., Ma, Y., et al. (2020) Fasting Blood Glucose at Admission Is an Independent Predictor for 28-Day Mortality in Patients with COVID-19 without Previous Diagnosis of Diabetes: A Multi-Centre Retrospective Study. Diabetologia, 63, 2102-2111.

https://doi.org/10.1007/s00125-020-05209-1

[14] Huang, I., Pranata, R., Lim, M.A., Oehadian, A. and Alisjahbana, B. (2020) C-Reactive Protein, Procalcitonin, D-Dimer, and Ferritin in Severe Coronavirus Disease-2019: A Meta-Analysis. Therapeutic Advances in Respiratory Disease, 14, Article ID: 1753466620937175 . https://doi.org/10.1177/1753466620937175

[15] Wu, C., Chen, X., Cai, Y., Xia, J., Zhou, X., Xu, S., et al. (2020) Risk Factors Associated with Acute Respiratory Distress Syndrome and Death in Patients with Coronavirus Disease 2019 Pneumonia in Wuhan, China. JAMA Internal Medicine, 180, 934-943. https://doi.org/10.1001/jamainternmed.2020.0994 